If you don't need change, maybe you don't need sex

SIR - Your News Feature 'Sex-starved and still surviving' (Nature 452, 678-680; 2008) about bdelloid rotifers sheds some much-needed light on this understudied group of organisms. But for those of us working with unicellular eukaryotes - protozoa and the like - this lack of sexual habit is not so scandalous. After all, the idea that sex is widespread among eukaryotes is based on relatively large organisms.

Still, a proper understanding of eukaryotic ecology and evolution must start with unicellular eukaryotes. These drive major ecological processes and form the principal part of the eukaryotic phylogenetic tree, whereas multicellular eukaryotes are mainly figureheads. Any textbook on evolution authored by a protozoon would give large multicellular organisms and their sexual problems little more attention than a footnote.

Being eukaryotes ourselves, it is interesting for us to know why some of our relatives are sexual beings and others are not. The sexual preferences of our cousins the rotifers are probably more akin to those of protozoa than to our own. Bdelloid rotifers share many features with protozoa apart from their lack of sex life, including small body size and very large populations. The adaptational reasons for the absence of sex are not fully understood. Part of the explanation may be that the microniches these small organisms inhabit have remained unchanged for millions of years - so mechanisms for substantial genetic change are not needed.

Flemming Ekelund, Regin Rønn Terrestrial Ecology, Biological Institute, University of Copenhagen, Øster Farimagsgade 2D, DK-1353 Copenhagen K, Denmark

\section{Ancient asexuals: darwinulids not exposed}

SIR - The paradox of sex, using bdelloid rotifers as an example of ancient asexuality, is highlighted in your News Feature 'Sex-starved and still surviving' (Nature 452, 678-680; 2008). But bdelloids are not the only certain ancient asexuals - there are other contenders for the title.

The box on darwinulid ostracods does no justice to research findings on other putative ancient asexuals. Sex in darwinulids has not been conclusively demonstrated. The three males in a single species of the darwinulid genus Vestalenula, found among thousands of females, did not have identifiable sperm (nor did any of the investigated females), suggesting that these specimens are nonfunctional atavisms.

Perhaps the most important result to emerge from the discovery of these males is that a ghost male of the model darwinulid species Darwinula stevensoni, supposedly described in 1870, can now be dismissed, because the morphology of the copulatory appendages of the Japanese males indicates

“Understanding our auditory pathways may inform us about why only some musical experiments,are successful Laurel Trainor, page 598 IN $\frac{1}{\text { RUNNING }}$ to advocate self-sufficiency in food because it regards reliance on international food import as a threat to domestic security.

In spite of this strict policy, the annual virtual-water import through food trade increased

sharply from 30 billion cubic metres in the 1990s to an average of 71 billion cubic metres a year between 2000 and 2004 (J. Liu et al. Water Int. 32, 78-90; 2007).

The increase is mainly due to the import of water-intensive crops, particularly soya beans. Virtual water is politically silent and economically invisible, and importing it is current practice in China.

China is confronted with

that the presumed penes of the $D$. stevensoni male were different parts of its anatomy.

Neither does $D$. stevensoni bear any genetic signature of recombination. You correctly note that it has very low nuclear genetic variability, but fail to mention that this is expected of any organism, asexual or sexual, that has active gene-homogenizing mechanisms, such as gene conversion or efficient DNA repair.

On the basis of the available evidence, bdelloid rotifers are ancient asexuals. Likewise, the species $D$. stevensoni has now been asexual for about 25 million years. To dismiss all darwinulids as putative asexuals is as wrong as claiming ancient asexual status for the group as a whole.

Koen Martens, Isa Schon Royal Belgian Institute of Natural Sciences, Freshwater Biology, Vautierstraat 29, 1000 Brussels, Belgium

\section{Time to break the silence around virtual-water imports}

SIR - Your News Feature 'More crop per drop' (Nature 452, 273-277; 2008) mentions that China has "unconsciously" turned to 'virtual-water' imports by importing food that requires large amounts of water to produce. Officially, however, the Chinese government continues water scarcity in several parts of the country, particularly in the North China Plain and the northwestern regions. Several studies have been published on the benefits of incorporating a virtual-water strategy in regional-water management and in food-trade policies for arid regions. These all indicate that importing virtual water into the North China Plain may well be more efficient than transferring 'real' water through the Southto-North Water Transfer Project - a controversial initiative now under construction to divert water from the Yangtze River to northern China $(\mathrm{H}$. Yang and A. Zehnder Water Resour. Res. 43, W12301; 2007).

If a virtual-water strategy had been taken into account in a feasibility study, the decision to invest half-a-billion euros in the transfer scheme might have been different. It would benefit China's development if the political silence around virtual-water transfer were broken and if the issue received more attention in planning water resources.

Junguo Liu Swiss Federal Institute of Aquatic Science and Technology (Eawag), Uberlandstrasse 133, PO Box $611, \mathrm{CH}-8600$ Dübendorf, Switzerland H. H. G. Savenije Delft University of Technology, Department of Water Management, PO Box 5048, 2601 DA Delft, The Netherlands 